\title{
Presentació de problemes de física amb Interactive Physics
}

\author{
Àngel Fontanet Rodríguez \\ IES Manuel Carrasco Formiguera, Barcelona \\ afontane@xtec.cat
}

En aquest article presento les possibilitats didàctiques del programa Interactive Physics (IP) de cara a presentar problemes de Física en forma de simulacions ("Fisips"). Finalment plantejo alguns interrogants sobre les dificultats per incorporar i estendre l'ús dels Fisips a l'ensenyament de la Física.

El programa Interactive Physics és un software educatiu que permet construir fàcilment simulacions de Física. La presentació de problemes de Física mitjançant simulacions és una eina educativa de gran abast perquè permet que l'alumnat analitzi el sistema físic objecte d'estudi en un entorn més comprensible i amable, la qual cosa pot contribuir a fer més entenedors els conceptes físics subjacents.

Tanmateix, cal ser previngut davant dels excessos d'optimisme digital. Els recursos basats en les TIC haurien d'estar curosament supeditades al discurs pedagògic. D'altra manera, a més de suposar un cost difícilment justificable poden tenir en el procés educatiu uns efectes desreguladors tan imprevisibles com negatius.

\section{INTRODUCCIÓ}

És palès que la creixent incorporació de les innovacions científiques i tecnològiques a la nostra societat reclama una alfabetització de la ciutadania en temes científics i tecnològics. Tanmateix, diversos estudis mostren un preocupant descens en el nivell dels coneixements científics entre l'alumnat de secundària i la disminució de vocacions científiques entre nois i noies (PISA, 2003).

Molts professors i professores de ciències són conscients d'aquesta problemàtica, i es detecta una clara voluntat de encetar una renovació didàctica de l'ensenyament de la ciència.

La majoria de les propostes d'innovació didàctica de la ciència aposten per incorporar les noves tecnologies de la informació i la comunicació (TIC) al quefer quotidià de l'aula. En aquest sentit, hi ha evidències que indiquen que les eines basades en les TIC poden ajudar a establir situacions d'aprenentatge on la més gran motivació de l'alumnat $i$ les millors sinèrgies col-laboradores creades entre els mateixos alumnes provoquen un aprenentatge més significatiu dels conceptes científics estudiats (Esquembre, 2004).

Tanmateix, un gran nombre d'aquestes noves propostes estan supeditades més a un imperatiu de novetat tecnològica que no pas a uns principis pedagògics sostinguts en models d'aprenentatge reconeguts (San Martín, 2006).

Una gran part de la responsabilitat d'aquesta situació rau en unes polítiques educatives que, malgrat mantenir un discurs positiu respecte la incorporació de les TIC a l'ensenyament, a hores d'ara no ha estat capaç d'articular estratègies reeixides en aquesta direcció. Això ha portat a una situació en que els projectes i iniciatives d'innovació educativa es multipliquen, duts a terme per professors i professores amb més entusiasme i voluntarisme que recursos; però que en la pràctica són d'abast limitat, tant des d'una perspectiva quantitativa com qualitativa, i amb un cost personal excessiu a mig o llarg termini.

\section{RESOLUCIÓ DE PROBLEMES}

La resolució de problemes és una activitat habitual en les classes de física. Els professors i professores de física dediquen una gran part del temps de les classes a la resolució de problemes perquè són considerats com un important recurs 
d'aprenentatge dels conceptes estudiats i, alhora, com un instrument fonamental d'avaluació.

La resolució del problema implica que l'alumnat posi en joc uns coneixements (conceptes, lleis,...), uns procediments (emissió de hipòtesi, càlcul matemàtic, interpretació de gràfiques,...) i , per descomptat, una actitud favorable.

\section{Elements funcionals d'un problema}

El problemes de Física tradicionals (els que es poden trobar en qualsevol llibre de text) tenen uns elements funcionals comuns (Perales, 2000):

- Descripció d'un sistema físic mitjançant text i imatge.

- Condicions experimentals que delimiten el fenomen físic objecte d'estudi.

- Simplificacions per ajustar el fenomen físic a un marc teòric simple.

- Valors d'alguns paràmetres.

- Preguntes amb consignes de resposta.

- Revisió de resposta.

Aquests elements no necessàriament hi són sempre tots. A més, hi poden estar presents de manera explicita o implícita. Per exemple:

\section{Problema}

Es deixa caure una pilota des d'una altura de 40 metres.

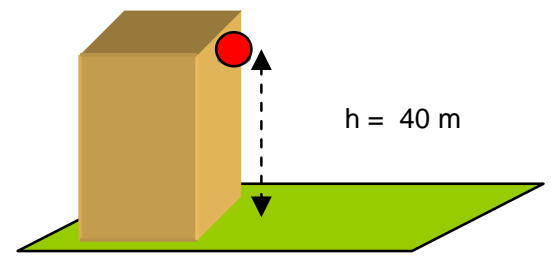

Calcular la velocitat, expressada en $\mathrm{Km} / \mathrm{h}$, amb la que arribarà al terra. (Suposar que no hi ha fregament amb l'aire).

\begin{tabular}{|l|l|}
\hline \multicolumn{1}{|c|}{ Element } & \multicolumn{1}{|c|}{ Exemple } \\
\hline $\begin{array}{l}\text { 1. Descripció } \\
\text { d'un sistema } \\
\text { físic mitjançant } \\
\text { text i imatge. }\end{array}$ & Pilota \\
\hline $\begin{array}{l}\text { 2. Condicions } \\
\text { experimentals }\end{array}$ & $\begin{array}{l}\text { Es deixa caure des d'una deter- } \\
\text { minada altura dins d'un camp }\end{array}$ \\
que delimiten & $\begin{array}{l}\text { gravitatori } \\
\text { el fenomen fí- } \\
\text { sic objecte }\end{array}$ \\
d'estudi. & \\
\hline
\end{tabular}

\begin{tabular}{|l|l|}
\hline $\begin{array}{l}\text { 3. Simplifica- } \\
\text { cions per ajus- } \\
\text { tar el fenomen } \\
\text { físic a un } \\
\text { marc teòric } \\
\text { simple }\end{array}$ & • $\begin{array}{l}\text { El camp gravitatori és el ter- } \\
\text { restre al nivell del mar }\end{array}$ \\
& $\begin{array}{l}\text { No hi ha fregament amb l'aire } \\
\text { L'objecte es considera puntual } \\
\text { - Arribar al terra significa que } \\
\text { cal considerar un instant infini- } \\
\text { tesimal abans de xocar amb } \\
\text { el terra }\end{array}$ \\
\hline $\begin{array}{l}\text { 4. Valors } \\
\text { d'alguns } \\
\text { paràmetres }\end{array}$ & $\begin{array}{l}\text { Velocitat inicial de la pilota }= \\
=0 \mathrm{~m} / \mathrm{s}\end{array}$ \\
\hline $\begin{array}{l}\text { Altura de caiguda }=40 \mathrm{~m} \\
\text { amb consig- } \\
\text { nes } \\
\text { de resposta }\end{array}$ & $\begin{array}{l}\text { Acceleració de la gravetat }= \\
=9,8 \mathrm{~m} / \mathrm{s}^{2}\end{array}$ \\
\hline $\begin{array}{l}\text { 6. Revisió de } \\
\text { resposta }\end{array}$ & $\begin{array}{l}\text { La velocitat amb la que arriba- } \\
\text { rà a terra } \\
\text { La velocitat ha de ser expres- } \\
\text { sada en } \mathrm{km} / \mathrm{h}\end{array}$ \\
\hline
\end{tabular}

\section{Classificacions dels problemes}

Els problemes de Física es poden classificar aplicant diferents criteris: segons el camp conceptual (cinemàtica, calor, hidrostàtica...), requeriments operatius (quantitatius o qualitatius), nombre de solucions (tancats o oberts), etc.

Entre els diferents criteris cal destacar el que considera el grau de definició estructural del problema segons el punt de vista de la persona que ha de resoldre el problema (Shin i al., 2003):

- Problemes fortament definits: tant els elements funcionals com els operadors estan, explícitament o implícita, prou clars.

- Problemes dèbilment definits: els elements funcionals i els operadors no estan prou clars.

Per exemple,

\begin{tabular}{|l|l|}
\hline $\begin{array}{l}\text { Problema } \\
\text { fortament definit }\end{array}$ & $\begin{array}{l}\text { Problema } \\
\text { dèbilment definit }\end{array}$ \\
\hline $\begin{array}{l}\text { Calcula el nombre } \\
\text { d'ampolles de 150 } \\
\mathrm{cm}^{3} \text { de capacitat que } \\
\text { es poden omplir amb } \\
\text { l'aigua de colònia } \\
\text { que hi ha en una } \\
\text { ampolla d'1 L de ca- } \\
\text { pacitat completament } \\
\text { plena. }\end{array}$ & $\begin{array}{l}\text { Cal omplir unes am- } \\
\text { polles petites amb } \\
\text { l'aigua de colònia } \\
\text { que hi ha en una } \\
\text { ampolla gran. Dispo- } \\
\text { sem de suficients } \\
\text { ampolles petites? }\end{array}$ \\
\hline
\end{tabular}




\section{Didàctiques de la resolució de problemes}

Pel que fa a l'ensenyament i aprenentatge de la resolució de problemes de Física, la metodologia didàctica més tradicional consta de tres etapes:

1) El professor enuncia una sèrie de problemes com a models

2) El professor fa una explicació detallada de l'algoritme de resolució

3) Els alumnes resolen problemes semblants al models

L'objectiu implícit d'aquesta seqüència metodològica és convertir el problema en simple exercici.

Una objecció important d'aquest mètode és que molts alumnes "estudien" els problemes de Física memoritzant "les fórmules" i els algoritmes de resolució del repertori de problemes models, però sense arribar mai a tenir un coneixement significatiu dels conceptes físics subjacents en el problema.

En l'actualitat, coexisteixen diferents enfocaments sobre la didàctica de les ciències i el paper de la resolució de problemes en l'ensenyament i aprenentatge de les disciplines científiques (Pozo, 2001). Algunes centren la seva atenció en millorar aspectes limitats de la metodologia tradicional (Oñorbe, 2003). Altres, en canvi, són més radicals i qüestionen els fonaments ideològics de la didàctica tradicional (Gil i al., 2002).

Dins d'aquest corrent més crític es troba el model didàctic de problemes com a investigació. Aquesta proposta considera que els autèntics problemes són els problemes dèbilment definits, perquè són els que més fomenten les habilitats cognoscitives, metacognitives i argumentatives de l'alumnat al voltant del fet científic. El problema com a investigació és plantejat inicialment com un estudi qualitatiu de la situació, sense dades numèriques, i, per tant, esdevé una recerca oberta on l'alumnat ha d'emetre hipòtesis, elaborar diferents estratègies de resolució, etc.

\section{SIMULACIONS AMB INTERACTIVE PHYSICS}

Una simulació és un software educatiu amb el qual els alumnes poden explorar i experimentar models de sistemes o processos físics mitjançant la realitat virtual de móns programats.

Seguint Sierra (2000), alguns dels avantatges més reeixits de les simulacions són:
- Permet reproduir fenòmens naturals difícilment observables de manera directa en la realitat per motius diversos: perillositat, escala de temps, escala espacial o cost econòmic del muntatge.

- L'alumne posa a prova les seves idees prèvies sobre el fenomen simulat mitjançant l'emissió d'hipòtesis pròpies, la qual cosa redunda en una més gran autonomia del procés d'aprenentatge.

- L'alumne comprèn millor el model físic utilitzat per explicar el fenomen en observar i comprovar interactivament la realitat que representa.

- La simulació possibilita extreure una part de la física subjacent en una determinada experiència, simplificant-ne l'estudi i facilitant la comprensió del fenomen.

- L'alumne pot modificar els diferents paràmetres i condicions inicials que apareixen en el model físic del simulador, ajudant-lo a formular les seves pròpies conclusions a partir de diferents situacions.

- La simulació evita a l'alumne els càlculs numèrics complexos, de manera que li permet concentrar-se en els aspectes més conceptuals del problema.

- La simulació ofereix a l'alumne una àmplia varietat de dades rellevants que facilita la verificació qualitativa i quantitativa de les lleis científiques.

- És possible tractar problemes físics amb un rerefons matemàtic complex, fent-los assequibles a l'alumne (sistemes no lineals, caos...)

Malgrat aquest Ilistat d'avantatges, els estudis portats a terme sobre la eficàcia didàctica de les simulacions en l'ensenyament i aprenentatge de la Física no demostren de manera concloent els beneficis que se'ls pressuposa (Jimoyianis i al., 2001). Una de les causes que podrien explicar aquesta insuficiència didàctica de les simulacions podria ser la falta de qualitat del software utilitzat a les aules (Rezaei i al, 2002).

\section{Interactive Physics}

Interactive Physics (IP) és un món virtual que simula el moviment de cossos sotmesos a les lleis de la Mecànica Newtoniana (Manual d'usuari IP, 2000; Fernández, Oro i Plana, 2006).

Mitjançant una interfície molt intuïtiva amb barres de menús, es poden definir les característiques (gravetat, fregament...) d'un món virtual i crear una gran varietat d'objectes (cossos, ressorts, politges...), tot definint els paràmetres de cadascun (posició, massa, mida...), que constitueixen els elements del sistema físic objecte d'estudi (fig.1). 


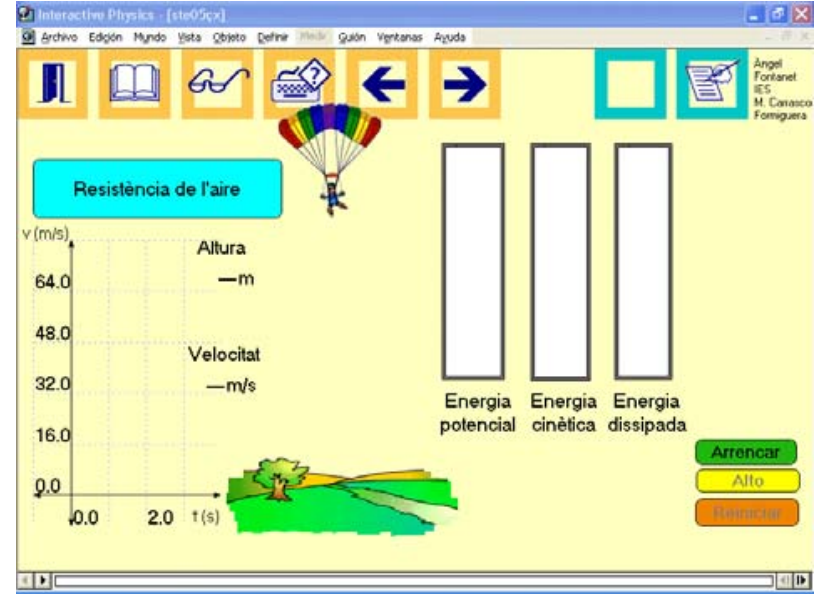

Figura 1. Pantalla de simulació IP.

Les principals característiques d'un Fisip, són:

- Requereixen ser executats en l'entorn d'IP.

- Poden ser reproduïts com un vídeo: aturar la imatge, visualitzar fotograma a fotograma, avançar, retrocedir...

- El món virtual és de dos dimensions.

- Es poden modificar els valors inicials dels paràmetres.

- Es poden definir equacions lògiques i matemàtiques que relacionin els valors de les variables.

- Es poden visualitzar els valors de les variables en temps real en diferents formes d'expressió.

Els Fisips construïts amb Interactive Physics poden contribuir a superar les dificultats que tenen un gran nombre d'alumnes quan han de resoldre problemes de Física. Els avantatges van en una mateixa direcció, millorar la presentació del problema de Física, però van, paradoxalment, en un doble sentit: augmentant alhora la definició i la indefinició. És a dir: eixamplen el problema cap a una definició més forta en alguns aspectes, perquè permeten augmentar els detalls de la presentació, però també cap a una definició més dèbil, perquè donen marge de decisió a l'alumnat.

\section{Elements dels Fisips}

En una primera aproximació, els tres elements fonamentals de qualsevol material didàctic sobre temàtica física i suport informàtic són les vistes, el model i, naturalment, l'objectiu didàctic (Fig. 2):

- Les vistes és tot allò que es mostra en pantalla: visualització del fenomen, textos, imatges, gràfics....
- El model d'un sistema físic ve definit per una sèrie de magnituds rellevants amb uns valors inicials fixats $i$ unes regles que governen com es relacionen entre si i com van canviant aquests valors amb el temps.

- L'objectiu didàctic imbrica el model i les vistes en una unitat amb sentit pedagògic.

Pel que fa a Interactive Physics, també trobem aquests elements, però allò més característic i rellevant d'Interactive Physics és la versatilitat del model. El potencial interactiu que es pot aconseguir mitjançant Interactive Physics, amb un esforç moderat de disseny (tret que el diferencia amb avantatge dels Fislets fets amb JAVA), és una de les característiques més atractives d'aquesta aplicació. (Fontanet, 2006).

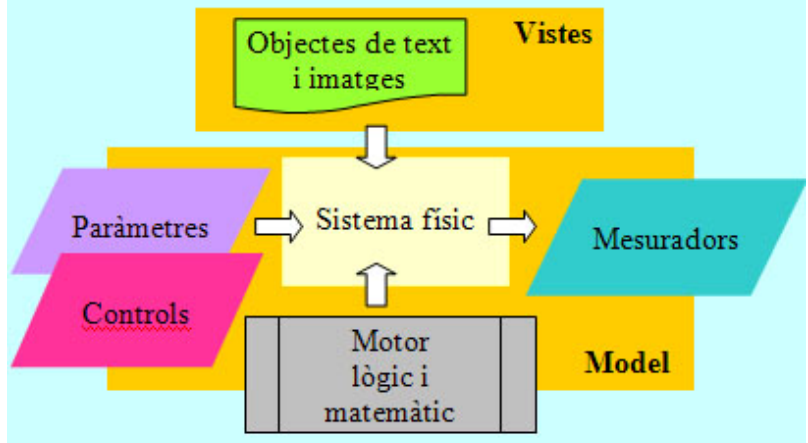

Objectiu didàctic

Figura 2. Elements dels Fisips

\section{Disseny de Fisips}

Un Fisip és l'element mínim que es pot construir amb IP. Tanmateix l'aprofitament didàctic d'un únic Fisip seria molt limitat. El potencial didàctic dels Fisips rau en grau mesura en la possibilitat d'acoblarlos formant una seqüència didàctica.

Cal dissenyar cada Fisip considerant la seva integració en una seqüència didàctica. Per a aquesta finalitat resulta molt útil dissenyar plantilles i petits prototips de parts del Fisip, sempre ben documentats. Aquests prototips han d'estar relativament poc elaborats amb una doble finalitat. En primer lloc, perquè així seran més flexibles i es podran adaptar a diferents seqüències didàctiques. En segon Iloc, perquè el que importa és assajar possibles solucions, i un prototip molt elaborat pot causar un estancament del procés o una ofuscació del dissenyador.

És convenient elaborar una plantilla de presentació comuna caracteritzada per una limitada gamma de colors, uns botons i una organització harmo- 
niosa dels diferents elements. L'objectiu és que l'alumnat es familiaritzi ràpidament $a m b$ els elements del Fisip i així es pugui concentrar a la tasca d'aprenentatge proposada. (La diversitat de dissenys és un greu problema quan s'aprofiten simulacions de diferents autors. Pensem en una analogia elemental: ens podem imaginar la dificultat de lectura d'un llibre escrit a l'atzar amb diferents tipus de lletra, grandària, espaiat, etc.?)

Porta al final de la seqüència i
dóna opció de sortir o tornar a
començar la seqüència didàctica

A la figura 1 hi ha un exemple de Fisip que mostra una plantilla amb una distribució de botons de desplaçament (fig. 3) a la part superior esquerra, unes icones de color verd informatives a la part superior dreta i uns botons d'execució i control a la part inferior dreta. De nou, la finalitat d'aquesta disposició és que l'alumne es familiaritzi fàcilment amb l'estructura formal del Fisip i, d'aquesta manera, pugui dedicar tot l'esforç a fer la tasca encomanada.

\section{REFLEXIÓ FINAL}

Un cop arribats fins aquí es podria pensar que aquesta comunicació és una més de tantes propostes messiàniques sobre les TIC en general o les simulacions en particular, ja siguin Fisips o Fislets.

L'esquema del discurs és clàssic. En primer Iloc es descriuen les dificultats de l'ensenyament i aprenentatge dins d'algun àmbit curricular. Tot seguit, es presenten els avantatges reals o imaginaris d'alguna innovació informàtica en concret (moltes vegades il.lustrades amb experiències personals) per, finalment, convidar a professors i professores a seguir iniciatives com la exposada.

Tanmateix, el propòsit últim d'aquesta comunicació va en sentit totalment contrari. Vull destacar que les magnifiques possibilitats educatives dels recursos TIC haurien d'estar supeditades al discurs pedagògic i no a l'inrevés. La manera asistemàtica, ocasional, artesanal... com es generen recursos TIC i com aquest són introduïts a la pràctica de l'aula, seguint sovint un patró oportunista, pot tenir en el procés educatiu uns efectes desreguladors tan imprevisibles com negatius.

\section{BIBLIOGRAFIA}

ESQUEMBRE, F. i al. (2004). Fislets: Enseñanza de la Física con material interactivo. Madrid: Pearson Prentice Hall.

FERNÁNDEZ, C. ORO, J. PLANA O. (consultat 2006). Materials de Formació del professorat. Simulacions amb Interactive Physics. Departament d'Educació. Generalitat de Catalunya.

FONTANET, À. (2006). Presentació de problemes de Física amb Interactive Physics. Treball de llicència retribuïda 2005-2006. Es pot trobar en: http://www.xtec.cat/ afontane/

GIL, D. i al. (2002). Defending Constructivism in Science Education. Science \& Education, 11, pp. 557-571.

INTERACTIVE PHYSICS (2000). Manual de usuario. MSC. Software. Redwood. City. California.

JIMOYIANNIS, V. i KOMIS, V. (2001). Computer simulations in physics teaching and learning. Computer \& Education, 36, pp. 183-204.

OÑORBE, A. (2003). Resolución de problemas. A Jiménez, M. P. (coord.): Enseñar ciencias. Barcelona: Graó.

PISA (2003): Informe del Programa per l'Avaluació Internacional dels Alumnes. Es pot trobar en www.pisa.oecd.org i en la web del Instituto Nacional de Evaluación y Calidad del Sistema Educativo (INECSE): http://www.ince.mec.es/pub/pubintn.htm 
REZAEI, A. R. i KATZ, L. (2002). Using computer assisted instruction to compare the inventive model and the radical constructivist approach to teaching physics. Journal of Science Education and Technology, 11 (4), pp. 367-380.

SAN MARTíN. A. (2006). Las nuevas tecnologías no conducen siempre a la "nueva ciudad de dios". Cuadernos de pedagogía, 281. pp. 70-73.

SHIN, N. i al. (2003). Predictors of well-structured and ill-structured problem solving in an astronomy simulation. Journal of Research in Scien- ce Teaching, vol.40, $\mathrm{n}^{\circ}$ 1, pp. 6-33. En la web: http://vdc.cet.edu/entries/illsps.htm hi ha una descripció molt detallada.

SIERRA, J. L. (2000). Informática y enseñanza de las ciencias. A Perales, F. J. (coord.): Didáctica de las ciencias experimentales. Alcoy: Editorial Marfil.

PERALES, F. J i al. (2000). Resolución de problemas. Madrid: Editorial Síntesis.

POZO, J. I. i GÓMEZ, M. A. (2001). Aprender y enseñar ciencia. Madrid: Editorial Morata. 